\title{
Fatigue Strength Prediction Formulae for Steels and Alloys in the Gigacycle Regime
}

\author{
Chaminda S. Bandara, Sudath C. Siriwardane, Udaya I. Dissanayake, and Ranjith Dissanayake
}

\begin{abstract}
Most existing fatigue strength prediction models contain parameters related to the critical size of non metallic inclusions or defects. Finding the critical size of the inclusion or defect which causes the fatigue failure is not easy. Further, obtaining experimental stress life curves for gigacycles is expensive and time consuming. Therefore it is important to discover simple but reliable fatigue strength prediction formulae that use easily obtainable material parameters while being independent from the size of inclusions or defects. This paper proposes a new formula for predicting fatigue strengths of steels in the gigacycle regime using the ultimate tensile strength and Vickers hardness as material parameters while introducing a reliable substitute to the critical inclusion size. The formula is verified using published experimental results for forty five steels. Another formula for predicting fatigue strengths of steels and alloys is proposed using more than hundred experimental fatigue strength values at various numbers of failure cycles in the gigacycle regime.
\end{abstract}

Index Terms - Fatigue strength, gigacycles, inclusion and defect, stress life curve, tensile strength.

\section{INTRODUCTION}

Fatigue life of components that are subjected to cyclic loading often exceeds the high cycle regime; i.e. $10^{7}$ cycles [1]. Structural parts such as connecting rods, crank shafts and helical springs experience more than $10^{10}$ cycles in their service lives [2]. Railway and offshore structures generally exceed $10^{8}$ cycles [3]. Most of the fatigue design codes [4] too provide stress life S-N curves up to $10^{9}$ cycles for designing elements in steel structures such as bridges. However, in designs, a fictive fatigue limit is often assumed at the end of the high cycle regime [2], [4].

Since the findings in the 1990s that there is no infinite fatigue life for metals [5], a lot of research has been done to develop experimental S-N curves, theoretical models and empirical relationships to predict fatigue strength $\left(\sigma_{w}\right)$ of metallic materials beyond the high cycle regime known as the gigacycle regime.

Manuscript received January 21, 2013, revised March 17, 2013.

This work was supported by the National Research Council of Sri Lanka under the Grant NRC 11-106.

Chaminda S. Bandara is a Research Fellow of the National Research Council of Sri Lanka, Structural Engineering Laboratory, Faculty of Engineering, University of Peradeniya, Peradeniya 20400, Sri Lanka (e-mail: chamindasbandara@yahoo.com; bandara@civil.pdn.ac.lk).

Sudath C. Siriwardane is an Associate Professor of the Department of Mechanical and Structural Engineering and Material Science, Faculty of Science and Technology, University of Stavanger, N-4036 Stavanger, Norway (e-mail: sasc.siriwardane@uis.no).

Udaya I. Dissanayake and Ranjith Dissanayake are with the Departmen of Civil Engineering, University of Peradeniya, Peradeniya 20400, Sri Lanka (e-mail: udissa@pdn.ac.lk, ranjith@fulbrightmail.org).
In the gigacycle regime, developing $\mathrm{S}-\mathrm{N}$ curves through experiments using material specimens requires sophisticated equipment, precise temperature control techniques and much time [1]. Therefore, it is necessary to develop fatigue strength prediction models (theoretical or empirical) with readily available or easily obtainable material parameters such as the ultimate tensile strength $\left(\sigma_{u}\right)$ and hardness.

The fatigue cracks in the high cycle regime are caused by surface defects or slip bands [6], [7] whereas the cracks in the gigacycle regime are mainly caused by non metallic inclusions or voids that exist in metals [6], [8]. After extensive research, Murakami and Endo [9] developed fatigue strength prediction models for the high cycle regime based on surface defects and internal voids or inclusions. The main parameters of these models are the size of defect or inclusion $(\sqrt{\text { area }})$ and Vickers hardness $(H v)$ [6], [9]. Liu et al. [1], [10], Wang et al. [4], Mayor et al. [8], [11] and Chapetti et al. [12] have all proposed modifications to Murakami's model in order to widen its applicability in the gigacycle regime.

In the existing models mentioned, the term $\sqrt{\text { area }}$ is an important parameter. There are many different non metallic inclusions and defects in metals; this makes measuring $\sqrt{\text { area }}$ of the inclusion or defect that causes the failure in the future, complex. Further, it has been shown that the formation of a granular bright facet (GBF) also called the optically dark area (ODA) is the initiation of a fatigue crack and that the term $\sqrt{\text { area }}$ in Murakami's models should be replaced with the size of GBF or ODA in the gigacycle regime [1], [12], [13]. All these complexities highlight the need for a model which is independent of the term $\sqrt{\text { area }}$.

To overcome this problem, this paper first proposes a simple and reasonably accurate alternative relation for $\sqrt{\text { area }}$. The proposed relation mainly consists of $\sigma_{u}$. Then it compares four existing fatigue strength prediction models and notes their limitations. Then, a new formula (model) is proposed to predict the fatigue strength of medium and high strength steels in the high and gigacycle regimes. The main feature of this formula is that it consists only of easily obtainable material parameters such as $H v$ and $\sigma_{u}$. The accuracy of the formula is confirmed and verified by comparing the predictions of the proposed formula with experimental fatigue strength values of steels. As this formula consists of local material parameters of each type of steel and verification is also limited to steel, it is named "the local gigacycle fatigue formula for steels" in the present paper. Also, an empirical formula (model) is proposed to predict the fatigue strength in the gigacycle regime by 
studying the experimental fatigue behavior of more than fifty steels and alloys. The main features of this formula are that it consists of only $\sigma_{u}$ as the material parameter and represents a significant range of steels and alloys. Therefore in this paper, this empirical formula is named "the global gigacycle fatigue formula for steels and alloys”.

\section{PROPOSED SUBSTITUTE FOR INCLUSION SIZE}

Microscopic examinations of fracture surfaces of test samples show both external and internal failures at high and gigacycle regimes; for example, Mayor et al. [11] observed that, for Bainitic $100 \mathrm{Cr} 6$ steel, $42 \%$ failure was caused by internal $\mathrm{Al}_{2} \mathrm{O}_{3}$ inclusions while $28 \%$ failure was caused by surface defects within the range of $2 \times 10^{6}$ to $10^{10}$ cycles. Further, Bayraktar et al. [13] developed formulae considering the effect of the position of inclusions or defects between the center and the surface of a specimen. As such, the position of an inclusion or defect is a major factor that affects $\sigma_{w}$.

The maximum stress intensity factor $K_{I \max }$ for fatigue cracks of the major failure mode (mode I) at an internal inclusion and an external defect are given by $0.5 \sigma_{a}(\pi \sqrt{\text { area }})^{1 / 2}$ and $0.65 \sigma_{a}(\pi \sqrt{\text { area }})^{1 / 2}$ respectively [6],

[9] where $\sigma_{a}$ is the applied stress. The critical inclusion or defect could be anywhere in or between the center and the surface. Therefore, we propose that the most appropriate value for the stress intensity factor $K_{I}$ in a simple model that captures the effect of the location of an inclusion or defect as the average of the two above values which is given by

$$
K_{I}=0.575 \sigma_{a}(\pi \sqrt{\text { area }})^{1 / 2}
$$

where $K_{I}$ is given in $\mathrm{MPa} \cdot \sqrt{\mathrm{m}}, \sigma_{a}$ is given in $\mathrm{MPa}$, and $\sqrt{\text { area }}$ is given in $\mathrm{m}$.

Experiments conducted at the stress ratio $\mathrm{R}=-1$ for non propagating crack lengths versus $K_{\text {I max }}$ show that the cracks are propagating for $K_{I \text { max }}$ in the range of $1.8 \mathrm{MPa} \cdot V_{\mathrm{m}}$ and 2.0 $\mathrm{MPa} \cdot \sqrt{\mathrm{m}}$ and that the threshold value of $K_{\text {I } \max }$ under which no cracks could initiate is approximately $1.8 \mathrm{MPa} \cdot \sqrt{\mathrm{m}}$ regardless of the size of the crack [6], [9]. Therefore, we propose that, for a propagating crack, the mean value for $K_{I}$ in the range 1.8 $\mathrm{MPa} \cdot \sqrt{ } \mathrm{m}$ to $2.0 \mathrm{MPa} \cdot V_{\mathrm{m}}$, (i.e. $1.9 \mathrm{MPa} \cdot \sqrt{\mathrm{m}}$ ) should be a reasonably accurate prediction. Substituting $1.9 \mathrm{MPa} \cdot \sqrt{ } \mathrm{m}$ for $K_{I}$ in (1), the effective minimum value for $\sqrt{\text { area }}$ can be simplified as

$$
\sqrt{\text { area }}=1.92 /\left\{\left(0.575 \sigma_{a}\right)^{2} \pi\right\}
$$

where, the units of the terms in (2) are the same as that in (1). Equations (1) and (2) are based on Murakami's research [6], [9], conducted in the high cycle regime at $10^{7}$ cycles [1], [10].

Therefore, replacing $\sigma_{a}$ with $\sigma_{w}$ at $10^{7}$ cycles in (2) should give a value for $\sqrt{\text { area }}$ that causes the fatigue failure at $10^{7}$ cycles.
TABLE I: COMPARISON OF EXPERIMENTAL VALUE AND PREDICTED VALUE USING (3) FOR $(\sqrt{\text { area }})^{1 / 6}$

\begin{tabular}{lccccc}
\hline \hline Steel & $\begin{array}{c}\text { Refer } \\
\text { ence }\end{array}$ & $\begin{array}{c}\sigma_{\mathrm{u}} \\
(\mathrm{MPa})\end{array}$ & $\begin{array}{c}\text { Experim } \\
\text { ental } \\
\sqrt{\text { area }} \\
(\mu \mathrm{m})\end{array}$ & $\begin{array}{c}\text { Experime } \\
\text { ntal } \\
(\sqrt{\text { area }})^{1 / 6} \\
\left(\mu \mathrm{m}^{1 / 6}\right)\end{array}$ & $\begin{array}{c}\text { Calculate } \\
\mathrm{d} \text { from }(3) \\
(\sqrt{\text { area }})^{1 / 6} \\
\left(\mu \mathrm{m}^{1 / 6}\right)\end{array}$ \\
\hline AZ91hp & {$[8]$} & 190 & 520 & 2.84 & 2.70 \\
AM60hp & {$[8]$} & 178 & 480 & 2.80 & 2.76 \\
AE42hp & {$[8]$} & 184 & 447 & 2.77 & 2.73 \\
AS21hp & {$[8]$} & 131 & 510 & 2.83 & 3.06 \\
A1Si9Cu3 & {$[8]$} & 216 & 781 & 3.03 & 2.59 \\
42CrMo4 & {$[4]$} & 1,530 & 20 & 1.65 & 1.35 \\
42CrMo4 & {$[4]$} & 1,530 & 13 & 1.53 & 1.35 \\
CrV & {$[4]$} & 1,800 & 25 & 1.71 & 1.28 \\
54SC6 & {$[4]$} & 1,692 & 22 & 1.67 & 1.30 \\
54SC6 & {$[4]$} & 1,692 & 30 & 1.76 & 1.30 \\
54SC7 & {$[4]$} & 1,800 & 25 & 1.71 & 1.28 \\
54SC7 & {$[4]$} & 1,800 & 22 & 1.67 & 1.28 \\
SUP10M3 & {$[4]$} & 1,828 & 14 & 1.55 & 1.27 \\
SUP10M6 & {$[4]$} & 1,841 & 29 & 1.75 & 1.27 \\
SUP9TM & & & & & \\
1 & {$[4]$} & 1,482 & 260 & 2.53 & 1.36 \\
\hline \hline
\end{tabular}

Provided that $\sigma_{w}$ at $10^{7}$ cycles is not known, the approximate upper bound fatigue limit (fictive) of a material in the high cycle fatigue regime is known and equal to $0.5 \sigma_{u}$ [6]. Therefore the value of $(\sqrt{\text { area }})^{1 / 6}$ in (2) can be simplified by substituting $0.5 \sigma_{u}$ for $\sigma_{a}$ in (2) and expressed as

$$
(\sqrt{\text { area }})^{1 / 6}=\left(14 / \sigma_{u}^{2}\right)^{1 / 6}
$$

where, the units of the terms in (3) are the same as that in (1).

The comparison of experimental and predicted values for $(\sqrt{\text { area }})^{1 / 6}$ given in Table I shows that (3) provides a reasonably accurate theoretical value for $(\sqrt{\text { area }})^{1 / 6}$. Further, the value of $\sqrt{\text { area }}$ varies with the applied stress that affects the failure life [9], [12]. The effect of this variation is adopted in Section IV when developing the fatigue strength prediction formula.

\section{EXISTING FATIGUE STRENGTH PREDICTION MODELS AND THEIR LIMITATIONS}

In order to develop a simplified fatigue strength prediction model, four existing models were first studied. The Murakami model [6], [9] which is given (for $\mathrm{R}=-1$ ) by

$$
\sigma_{w}=\beta \cdot(H v+120) /(\sqrt{\text { area }})^{1 / 6}
$$

where, the value of the parameter $\beta$ is 1.43 for surface defects or inclusions, 1.41 for defects or inclusions in contact with the surface, and 1.56 for internal defects or inclusions. In (4), $\sigma_{w}$ is in $\mathrm{MPa}, H v$ is in $\mathrm{kgf} / \mathrm{mm}^{2}$, and $\sqrt{\text { area }}$ is in $\mu \mathrm{m}$. The main limitation of this model is that it is valid only for the high cycle regime for $10^{7}$ cycles [10]. The main difficulty of using this model is that it requires a prior prediction of the location of the inclusion or defect that causes the damage in the future. 
Wang et al. [3] proposed modifications to (4) for predicting $\sigma_{w}$ at any number of cycles to failure $\left(N_{f}\right)$ defining $\beta$ in the form

$$
\beta=\beta_{1}-\beta_{2} \log N_{f}
$$

where, the material and location related constants $\beta_{1}$ and $\beta_{2}$ are 3.09 and 0.12 respectively for internal inclusions and 2.79 and 0.108 respectively for surface defects. The Difficulty of using this model is that it also requires a prior prediction of the location of the inclusion or defect that causes the damage in the future.

The modified Murakami model by Liu et al. [1] for gigacycle regime for $\mathrm{R}=-1$ and for $10^{9}$ failure cycles is given by

$$
\sigma_{w}=2.7(H v+120)^{15 / 16} /(\sqrt{\text { area }})^{3 / 16}
$$

where, the units are as same as those in (4). The limitations of (6) are that it is valid only for failures due to internal inclusions or defects and for $10^{9}$ cycles.

The fatigue life prediction model of Chapetti et al. [12] is a relation between $\sigma_{w}, N_{f}$, the radius of the optically dark area $\left(R_{O D A}\right)$, the inclusion radius $\left(R_{i}\right)$, the maximum inclusion radius $\left(R_{i \text { max }}\right)$, and the threshold stress intensity factor range $\left(\Delta K_{t h}\right)$. For $\mathrm{R}=-1$, the relation is given by

$$
\begin{gathered}
\sigma_{w}=256 \cdot \Delta K_{t h} / \sqrt{R_{i \cdot \max }} \\
\Delta K_{t h}=0.004(H v+120) \cdot\left(3 R_{i \cdot \max }\right)^{1 / 3} \\
R_{O D A} / R_{i}=0.25 N_{f}^{0.125}
\end{gathered}
$$

where $\sigma_{w}$ is in $\mathrm{MPa}, H v$ is in $\mathrm{kgf} / \mathrm{mm}^{2}, R_{O D A}, R_{i}$, and $R_{i}^{\max }$ are in $\mu \mathrm{m}$, and $\Delta K_{t h}$ is in $\mathrm{MPa} \cdot \sqrt{\mathrm{m}}$. The maximum value of $\Delta K_{t h}$ in the expression is $10 \mathrm{MPa} \cdot V_{\mathrm{m}}$ and $R_{O D A}$ is approximated to $3 R_{i}^{\max }$ [12]. The limitation of this model is that it is valid only for failures due to internal inclusions or defects.

\section{Proposed Local Gigacycle Fatigue Formula For STEELS}

\section{A. The Proposed Model}

The requirements of the proposed model are that it should be simple and a single formula that addresses the limitations and difficulties of the existing models. For this purpose, in this paper, we propose modifications to the Murakami model following the modifications introduced by Wang et al, described in Section III.

In order to avoid location related limitations and difficulties, we propose location independent values for $\beta_{l}$ and $\beta_{2}$ that are estimated as 2.41 and 0.109 respectively. (These values were obtained by using optimization techniques for minimizing the error between the experimental fatigue strengths with model predicted fatigue strengths for forty five steels). It is to be noted that $\beta_{1}$ includes the effect of the variation of $\sqrt{\text { area }}$ with the number of cycles for $N_{f}>10^{7}$. Combining (4) and (5) and substituting $\beta 1$ and $\beta_{1}$ with 2.41 and 0.109 respectively, $\sigma_{w}$ can be expressed as

$$
\sigma_{w}=\left(2.41-0.109 \log N_{f}\right) \cdot(H v+120) /(\sqrt{\text { area }})^{1 / 6}
$$

Substituting $(\sqrt{\text { area }})^{1 / 6}$ in (10) with $\left(14 / \sigma_{\mathrm{u}}{ }^{2}\right)^{1 / 6}$ from (3) with the relevant units, $\sigma_{w}$ at any $N_{f}>10^{7}$ cycle can be expressed as

$$
\sigma_{w}=0.001(H v+120) \cdot\left(155-7 \log N_{f}\right) \cdot \sigma_{u}^{1 / 3}
$$

where $\sigma_{w}$ and $\sigma_{u}$ are in $\mathrm{MPa}$, and $H v$ is in $\mathrm{kgf} / \mathrm{mm}^{2}$.

If one of the two parameters $\sigma_{u}$ or $H v$ is not available, the approximate relationship of $\sigma_{u}$ and $H v$ [6], [9] modified and given by; $\sigma_{u}=3.33 H v$ may be used to evaluate the unavailable parameter. The constant 3.33 in this expression is obtained by plotting $\sigma_{u}$ versus $H v$ for forty steels in this study (Fig.1).

\section{B. Verification of the Model}

The verification of the predictions of the proposed model was done by comparing the experimental fatigue strengths at known $N_{f}$ (from published research work for forty five steels by others [1],[3],[10],[12],[14]-[25]) with calculated fatigue strengths at the same $N_{f}$ by using (11) as shown in Fig. 2 for the range $10^{6}<N_{f}<10^{10}$. The tensile strengths of steels used are in the range $800 \mathrm{MPa}$ to $2025 \mathrm{MPa}$. The experimental stress ratio $\mathrm{R}=-1$, loading frequencies; in the high cycle regime in the range $20 \mathrm{~Hz}$ to $165 \mathrm{~Hz}$ and that in the gigacycle regime in the range $20 \mathrm{kHz}$ to $30 \mathrm{kHz}$. Carbon equivalency values of selected steels are less than $1 \%$.

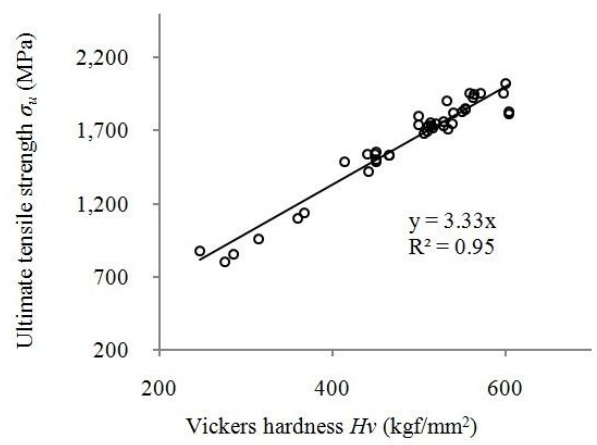

Fig. 1. Relationship between $\sigma_{u}$ and $H v$ for steels.

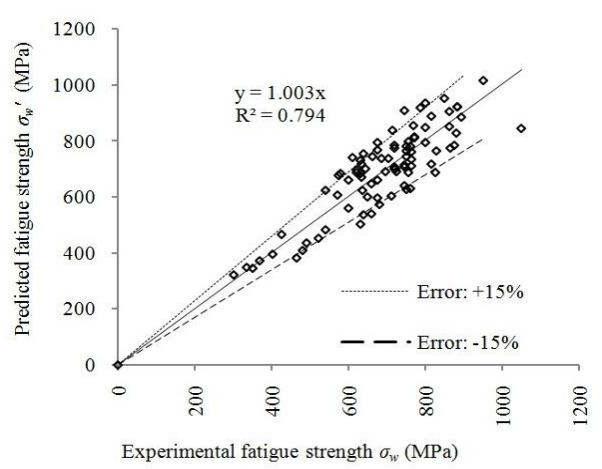

Fig. 2. Experimental fatigue strength versus calculated fatigue strength by using (11). 
The comparison exhibits that the model predicts $\sigma_{w}$ fairly accurately. The fatigue strength predictions at a given number of cycles for $95 \%$ of the heats of steels used in the study are within $20 \%$ error margin while $76 \%$ are within $15 \%$ error margin (Fig. 2).

\section{Proposed Global Gigacycle Fatigue Formula FOR STEELS AND ALLOYS}

A relationship between $\sigma_{w}$ and $\sigma_{u}{ }^{1 / 3}$ is observed in (11). Therefore, an empirical analysis was performed by plotting experimental observations of $\sigma_{w} \log N_{f} / \sigma_{\mathrm{u}}{ }^{1 / 3}$ versus $\sigma_{w} \log N_{f}$ for the steels used in Section IV with nine aluminium and magnesium alloys obtained from published research work [2],[8],[25]. The tensile strengths of alloys used are in the range $131 \mathrm{MPa}$ to $641 \mathrm{MPa}$ and $\mathrm{R}=-1$.

The variation shown in Fig. 3 reveals a simplified formula for fatigue strength of steels and alloys in the gagacycle regime as

$$
\sigma_{w}=\gamma \sigma_{u}^{\eta} / \log N_{f}
$$

where $\gamma$ and $\eta$ are calculated as 0.707 and 1.214. The units of both $\sigma_{w}$ and $\sigma_{u}$ are in $\mathrm{MPa}$ and $N_{f}$ is in the range $10^{6}$ to $10^{10}$ cycles.

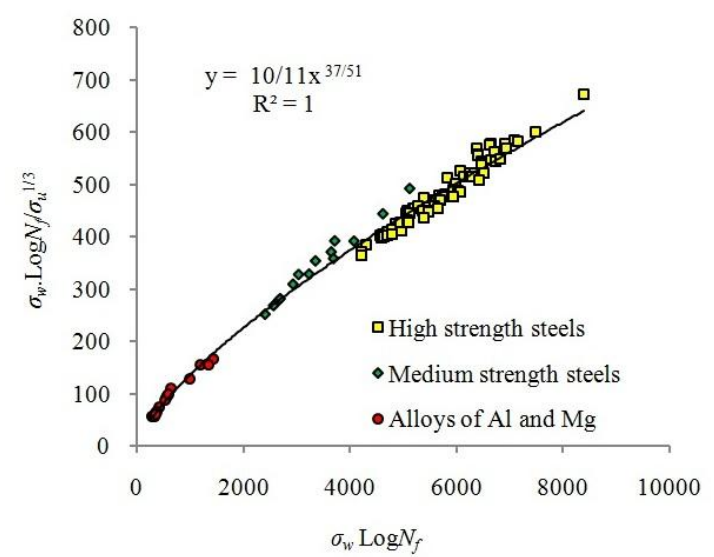

Fig. 3. Relationship between $\sigma_{w}, \sigma_{u}{ }^{1 / 3}$ and $N_{f}$ for steels and alloys.

\section{DISCUSSION}

The applicability of the two proposed gigacycle fatigue formulae in this study is wide ranging. These formulae can be applied for general engineering designs such as steel elements in bridges, offshore structures, mechanical structures and components where the design S-N curves are prepared using probability based approaches with safety factors. As the formulae are simple, they could be easily used in computer based programming and design applications. The relative ease of obtaining the material parameters required for these models and the fact that they can be presented in a single formula are their main advantages.

While the term $\sqrt{\text { area }}$ is not used in the proposed models, it should not be assumed that there is no effect from this term for the fatigue strength: here, $\sqrt{\text { area }}$ is simply substituted by a reasonably approximate term related to $\sigma_{u}$. Such approximation is possible due to the fact that $\sigma_{u}$ has a good relationship with the properties, shapes, sizes and population densities of inclusions or defects in a metallic material [6].

Hardness, especially Vickers hardness, has a close relationship with the inclusions or defects in metals [6], [9]. However, depending on various material properties (carbon and alloy contents, treatment process and production process etc.) the correlation of $\sigma_{w}, \sqrt{\text { area }}, H v$ and $\sigma_{u}$ varies. Therefore, a model that combines all these and any other related parameters should provide better strength predictions. This phenomenon explains the efficiency of the local model (which is developed using both $\sigma_{u}$ and $H v$ ) that provides better predictions than the global model (which is based only on $\sigma_{u}$ ).

Although there are no limitations for the proposed models except the material and range of cycles, it was observed that the steels with $\sigma_{u}>2,000 \mathrm{MPa}, \sigma_{w}>900 \mathrm{MPa}$ and carbon equivalency $>1 \%$ show a slight deviation from the expected predictions. Therefore, further studies and modifications are required for these areas. The method proposed in this paper could be applied to other metals in a future study through which material related parameters $\left(\beta_{1}, \beta_{2}, \gamma, \eta\right)$ could be discovered and the material limitations of the proposed models could be eliminated.

\section{CONCLUSIONS}

In this paper, a reliable approach for estimating the term $(\sqrt{\text { area }})^{1 / 6}$ was proposed. Then, two simplified formulae were proposed to overcome the limitations and difficulties of existing experimental and theoretical approaches for predicting the fatigue strength of steels and alloys in the gigacycle regime.

The first formula is a local formula for steels. The distinctive feature of this formula is that it is independent of the term $\sqrt{\text { area }}$ and only consists of $\sigma_{u}, H v$ and $N_{f}$. The formula is verified for forty five steels.

The second is an empirical global formula introduced for steels and alloys. The formula was developed using fatigue strengths of forty five steels and nine alloys. This formula is proposed as the most simplified fatigue strength prediction formula for a given $N_{f}$ as it only requires $\sigma_{u}$.

\section{ACKNOWLEDGMENT}

Authors would like to thank Dr. K. Karunananda for his valuable assistance.

\section{REFERENCES}

[1] Y. B. Liu, Z. G. Yang, Y. D. Li, S. M. Chen, S. X. Li, W. J. Hui, and Y.Q. Weng, "Dependence of fatigue strength on inclusion size for high strength steels in very high cycle fatigue regime," Mater. Sci. Eng A, vol. 517, pp. 180-184, 2009

[2] C. M. Sonsino, "Course of SN curves especially in the high-cycle fatigue regime with regard to component design and safety," Int. $J$ Fatigue, vol. 29, pp. 2246-2258, 2007.

[3] Q. Y. Wang, J. Y. Berard, A. Dubarre, G. Baudry, S. Rathery, and C. Bathias, "Gigacycle fatigue of ferrous alloys," Fatigue. Fract. Eng. Mater. Struct., vol. 22, pp. 667-672, 1999.

[4] Euro code 3: Design of steel structures, Part 1-9: Fatigue, CEN: Brussels: 2004.

[5] C. Bathias, "There is no infinite fatigue life in metallic materials," Fatigue. Fract. Eng. Mater. Struct., vol. 22, no. 7, pp. 559-565, July 1999. 
[6] Y. Murakami, Metal fatigue: effects of small defects and non metallic inclusions, 1st ed. Oxford, U.K: Elsevier, 2002.

[7] H. O. Fuchs and R. I. Stephens, Metal fatigue in engineering, 1st ed. New York, U.S.A: John Wiley, 1980.

[8] H. Mayer, M. Papakyriacou, B. Zettl, and S. E. Stanzl-Tschegg, "Influence of porosity on the fatigue limit of die cast magnesium and aluminium alloys," Int. J. Fatigue, vol. 25, pp. 245-256, 2003.

[9] Y. Murakami and M. Endo, "Effects of hardness and crack geometries on $\Delta \mathrm{K}_{\text {th }}$ of small cracks emanating from small defects," in The behavior of short fatigue cracks, K. J. Miller, and E. R. de los Rios, Eds. London, Mechanical Engineering Publications, 1986, pp. 275-293.

[10] Y. B. Liu, Y. D. Li, Z. G. Yang, S. M. Chen, W. J. Hui, and Y. Q. Weng, "Prediction of the S-N curves of high strength steels in the very high cycle fatigue regime," Int. J. Fatigue, vol. 32, pp. 1351-1357, 2010.

[11] H. Mayer, W. Haydn, R. Schuller, S. Issler, and M. Bacher-Hochst, "Very high cycle fatigue properties of bainitic high carbon-chromium steel under variable amplitude conditions," Int. J. Fatigue, vol. 31, pp. 1300-1308, 2009.

[12] M. D. Chapetti. (2006). Ultra-high cycle fatigue in high strength steels, Conamet, SAM. [Online]. Available: htt://www.materiale-sam.org.ar/sitro/bibliotecu/g6.pdf

[13] T. Wu, T. Mo, W. Chen, and E. Bayraktar, "Theoretical analysis of plastic zone of a circle crack under gigacycle fatigue regime," Archives of Computational Materials Science and Surface Engineering," vol. 1, no. 4, pp. 245-251, 2009.

[14] Q. Y. Wang, C. Bathias, N. Kawagoishi, and Q. Chen, "Effect of inclusion on subsurface crack initiation and gigacycle fatigue strength," Int. J. Fatigue, vol. 24, pp. 1269-1274, 2002.

[15] NRIM. (2005). Fatigue datasheet 97, [Online]. Available: http://mits.nism.go.jp/en/../html

[16] I. M. Garcia, D. G. Montiel, and C. Bathias, "Fatigue life assessment of high-strength low alloy steel at high frequency," The Arabian J. Sci. Eng., vol. 33, pp. 237-247, 2008.

[17] NRIM. (1978). Fatigue datasheet 44, [Online]. Available: http://mits.nism.go.jp/en/../html

[18] NRIM. (2008). Fatigue datasheet 104, [Online]. Available: http://mits.nism.go.jp/en/../html

[19] Y. Yu, J. L. Gu, L. Xu, F. L. Shou, B. Z. Bai, and Y. B. Liu, "Very high cycle fatigue behaviors of $\mathrm{Mn}-\mathrm{Si}-\mathrm{Cr}$ series Bainite/Martensite dual phase steels," Mater. Des., vol. 31, pp. 3067-3072, 2010.

[20] Y. D. Li, S. M. Chen, Y. B. Liu, Z. G. Yang, S. X. Li, W. J. Hui, and Y. Q. Weng, "The characteristics of granular-bright facet in hydrogen pre-charged and uncharged high strength steels in the very high cycle fatigue regime," J. Mater. Sci., vol. 45, pp. 831-841, 2010.

[21] S. Nishijima and K. Kanazawa, "Stepwise S-N curve and fish-eye failure in gigacycle fatigue," Fatigue Fract. Eng. Mater. Struct., vol. 22, pp. 601-607, 1999.

[22] Y. D. Li, Z. G. Yang, S. X. Li, Y. B. Liu, S. M. Chen, W. J. Hui, and Y. Q. Weng, "Effect of hydrogen on fatigue strength of high-strength steels in the VHCF regime," Adv. Eng. Mater., vol. 11, no. 7, pp. 561-567, 2009.

[23] Z. Duan, X. F. Ma, H. J. Shi, R. Murai, and E. Yanagisawa, "Gigacycle fatigue behavior of two SNCM439 steels with different tensile strengths," Acta. Mech. Sin., vol. 27, no. 5, pp. 778-784, 2011.

[24] Y. Furuya, S. Matsuoka, T. Abe, and K. Yamaguchi, "Gigacycle properties of high-strength low-alloy steel at $100 \mathrm{~Hz}, 600 \mathrm{~Hz}$ and 20kHz," Scripta. Mater., vol. 46, pp. 157-162, 2002.

[25] A. M. A. C. S. Bandara, P. B. R. Dissanayake, U. I. Dissanayake, and S. A. S. C. Siriwardane, "A new approach for predicting the fatigue strength of steels and aluminium alloys in high and gigacycle regimes," presented at the International Conference on Sustainable Built Environment, Kandy, Sri Lanka, Dec. 14-16, 2012.

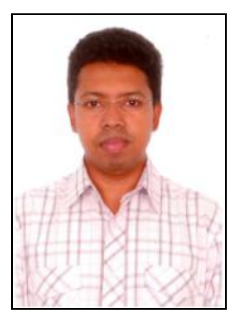

Chaminda S. Bandara was born in Sri Lanka on 14-04-1973. He obtained his B.Sc. Engineering (honors) Degree specializing in the field of Civil Engineering in January 2001 and his MSc. Engineering Degree specializing in the field of Structural Engineering in April 2011 from the University of Peradeniya, Sri Lanka.

He is a Research Fellow of the National Research Council of Sri Lanka and a Ph.D. Researcher at the Faculty of Engineering, University of Peradeniya, Peradeniya 20400, Sri Lanka. He has worked as a Senior Engineer in Six Construct Ltd., (U.A.E.) a Senior Engineer in MTHogjaard a/s (Sri Lanka), an Engineer in Taisei Corporation (the Maldives, Ghana and Sri Lanka), and an Engineer in KDL Construction Co. Ltd., (Sri Lanka). He has published several papers based on research titled, "Behavior of Cantilever Slabs in Blast Environment," Bandara and Dissanayake, in the Journal of Civil Engineering and Architecture, UAS: David Publishing, 2012, "Sustainable Solution for Retrofitting of Bridges Damaged by Floods," Bandara and Dissanayake in the proceedings of the $8^{\text {th }}$ IIIRR Annual International Conference, Kumomoto University, Kumamoto, Japan: 2011, "Future Life Evaluation of Existing Bridges," Bandara et al., in the proceedings of the $2^{\text {nd }}$ ICSBE International Conference, University of Peradeniya, Kandy, Sri Lanka: 2012. He has conducted research work on ferrocement, vibration actions on structures, blast effects on structures and effects of natural disasters on structures. He is currently conducting research on Fatigue Life Evaluation of Steel Structures.

Eng. Bandara is a Graduate of the Institute of Civil Engineers: United Kingdom, An Associate Member of the Institute of Engineers: Sri Lanka, Institute of Certified Professional Managers: Sri Lanka, and the Green Building Council of Sri Lanka.

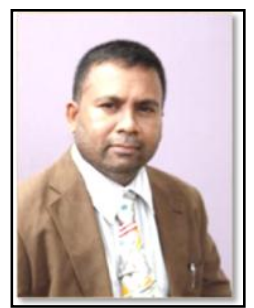

Ranjith Dissanayake was born in Sri Lanka on 21-11-1963. He obtained his B.Sc. Engineering (honors) Degree specializing in the field of Civil Engineering in 1991 from the University of Peradeniya, Sri Lanka. He obtained his M. Engineering Degree and Ph.D. (specializing in the field of Structural Engineering in) in 1995 and 1998 respectively from Ehime University, Japan.

$\mathrm{He}$ is a Professor in Civil Engineering at the University of Peradeniya, Peradeniya 20400, Sri Lanka. He has chaired four international conferences: Mitigation of the Risk of Natural Hazards (ICMRNR) of IIIRR in 2007, Sustainable Built Environment (ICSBE) in 2010, Structural Engineering, Construction and Management (ICSECM) in 2011 and Sustainable Built Environment (ICSBE 2012 / co-chair) in 2012. He has published more than 100 journal papers; a paper titled "Lessons Learnt from Tsunami Damage in Sri Lanka" was awarded the Overseas Prize of the Institution of Civil Engineers (ICE), Unite Kingdom in 2007. His research interests are: steel structures, seismic retrofitting of structures, structural health monitoring, structural optimization, disaster mitigation and sustainable built environment.

Professor Dissanayake is a Fulbright Scholar (2008), Columbia University, USA, an Endeavour Fellow, Monash University, Australia (2008), JASSO Research Fellow, Ehime University, Japan (2007) and Monbusho Scholar (1992-1998), Japan. He was awarded the Australian Alumni Excellence Award in 2012 and the Young Scientist Award in 2007 for Excellence in Scientific Research by National Science and Technology Commission of Sri Lanka. Professor Dissanayake is a Fellow of the Institution of Engineers Sri Lanka (IESL), a Fellow of the International Institute for Infrastructure Renewal and Reconstruction (IIIRR), a Member of the Society of Structural Engineers Sri Lanka (SSESL) and a Member and the Technical and Education Director of the Green Building Council of Sri Lanka (GBCSL). 